\title{
Lake-level variations of Lago Fagnano, Tierra del Fuego: observations, modelling and interpretation
}

\author{
Andreas RICHTER*, Jose Luis HORMAECHEA ${ }^{1)}$, Reinhard DIETRICH, Raúl PERDOMO ${ }^{2}$, Mathias FRITSCHE, \\ Daniel DEL COGLIANO ${ }^{2)}$, Gunter LIEBSCH and Luciano MENDOZA ${ }^{2)}$ \\ Technische Universität Dresden, Institut für Planetare Geodäsie, 01062 Dresden, Germany \\ ${ }^{1)}$ Estación Astronómica Río Grande, Argentina \\ ${ }^{2)}$ Universidad Nacional de La Plata, Facultad de Ciencias Astronómicas y Geofísicas, Argentina \\ *email corresponding author: richter@ipg.geo.tu-dresden.de
}

\begin{abstract}
The lake-level variations of Lago Fagnano, the largest lake in Tierra del Fuego, southernmost South America, on time scales from a few minutes to three years are investigated using a geodetic approach and applying the tools of time series analysis. Based on pressure tide gauge records at three locations in the lake precise lake-level time series are derived. The analysis of the observed variations in space, time and frequency domain leads to the separation of the principal force-response mechanisms. We show that the lake-level variations in Lago Fagnano can be described essentially as a combination of lake-level shift and tilt and of surface seiches. Regarding the lake-level response to air-pressure forcing, a significant departure from the inverse barometer model is found. Surface seiches dynamics are particularly intensive in Lago Fagnano pointing towards exceptionally low dissipative friction. An undisturbed series of seiches lasting eleven days is presented; and at least eleven longitudinal modes are identified. Based on the characterisation of the main contributions in space and time as well as their relation to the driving forces, a model for the transfer of the lake-level variations at a reference point to an arbitrary location in the lake with an accuracy of $1 \mathrm{~cm}$ is developed.
\end{abstract}

Key words: hydrodynamics, lake level, surface seiches, tide gauge, time series analysis

\section{INTRODUCTION}

Lago Fagnano is the largest lake in Tierra del Fuego, the archipelago at the southern tip of South America. Only few results of limnological research of this lake have been reported in the literature. This fact might be explained by the lake's remote location, but does certainly not reflect any lack of attraction to limnological and related scientific interest.

On the one hand, Lago Fagnano represents an outstanding individual among the lakes on earth. First, it is the southernmost lake of its size outside Antarctica, and due to this exposed location it bears a unique potential as a paleoclimate archive (Waldmann et al. 2008). Second, its origin, formation and present geological setting are closely related to its location on the active tectonic plate boundary between the South America and Scotia plates (Lodolo et al. 2003). And third, the shape and orientation of the lake's basin provides nearly ideal conditions for the study of particular hydrodynamic phenomena (Richter et al. 2009).

On the other hand, Lago Fagnano can be regarded as one representative for a chain of lakes of comparable size and geographical setting running southward along the eastern slope of the Andean Cordillera of Patagonia and comprising Lagos Nahuel Huapi, Buenos Aires/General Carrera, San Martín/O'Higgins, Viedma and Argentino, among others.
For the understanding of energy and mass flux, of chemical and biological processes in a lake the knowledge of its hydrodynamics is fundamental. Here we regard the variations of the lake level of Lago Fagnano as one of the manifestations and as an indicator of the hydrodynamics of the lake. Based on tide gauge records, the vertical motions of the water surface on a wide spectrum of time scales from a few minutes to several years are determined, analyzed and described in space, time and frequency domain. These results shall permit to predict the lake-level variations in Lago Fagnano, which is realised by an operational model.

After a brief geographic, morphometric, and climatological characterisation of Lago Fagnano, the procedure of lake-level determination is summarised. Then the observed lake-level variations are presented and related to different phenomena and driving forces; first for long-term variation contributions with periods of more than a few hours, and subsequently for shortperiod variations. In particular, an exceptional intensity of resonant surface seiches in terms of both the duration of oscillation series and the number of identified modes is revealed. Finally, the discussed phenomena are combined to an overall picture of the lake-level variations in Lago Fagnano, and some implications and applications are outlined.

\section{LAGO FAGNANO}

Lago Fagnano traverses the southern part of Isla Grande de Tierra del Fuego in E-W direction (Fig. 1). 


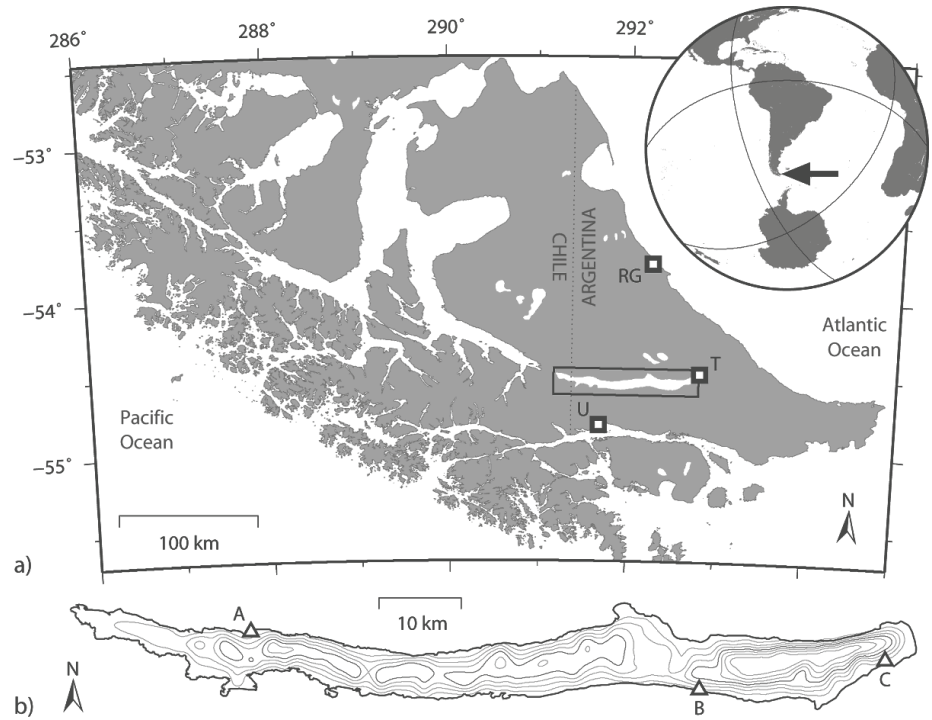

Fig. 1. a) Map of Tierra del Fuego. Box marks the location of Lago Fagnano, squares show the towns of Río Grande (RG), Tolhuin $(\mathrm{T})$, and Ushuaia (U). In the inset, the region under investigation is indicated by the arrow. b) Contour and bathymetry of Lago Fagnano. Triangles depict the tide gauge sites A, B, C; the bathymetric model (contour interval $25 \mathrm{~m}$ ) is derived from echo-sounding profiles by Lippai et al. 2004.

Its water surface extends over the national territories of Argentina and Chile between $68^{\circ} 48.6^{\prime}$ and $67^{\circ} 12.7^{\prime} \mathrm{W}$, $54^{\circ} 29.9^{\prime}$ and $54^{\circ} 36.9^{\prime} \mathrm{S}$.

Lago Fagnano owes its formation to tectonic processes associated with the Magallanes-Fagnano fault system which represents the recently active left-lateral transform boundary between the South American and Scotia tectonic plates in this region (Lodolo et al. 2003). The second main factor responsible for the present appearance of Lago Fagnano consists in the repeated glaciation of the region in the late Pliocene and Pleistocene (Rabassa et al. 2000). During at least three glacial advances the lake's valley was occupied by a substantial ice lobe that deposited the moraines which today form the eastern end of the lake as well as the silt, in which the steep lake shores are carved.

Lago Fagnano is $104 \mathrm{~km}$ long and on average $6 \mathrm{~km}$, maximum $10 \mathrm{~km}$ wide. The lake covers an area of 600 $\mathrm{km}^{2}$. According to echo sounding measurements by Lippai et al. (2004) the maximum depth of Lago Fangano is $204 \mathrm{~m}$. A bathymetric model, displayed in figure $1 \mathrm{~b}$, has been derived from these data. It shows that the central and eastern parts of the lake floor are dominated by two basins separated by a sill with a maximum depth of $80 \mathrm{~m}$. The mean water depth of the lake amounts to $70 \mathrm{~m}$ and its water volume to $41 \mathrm{~km}^{3}$. The basin geometry of Lago Fagnano can be characterised as slightly convex-meso (Håkanson 1981).

Lago Fagnano is an oligotrophic (Mariazzi et al. 1984), warm monomictic lake. The drainage basin extends over an area of $3042 \mathrm{~km}^{2}$ and elevations from $27 \mathrm{~m}$ (lake level) to approximately $1000 \mathrm{~m}$ above sea level. It is characterised by a pluvio-nival river discharge regime. The lake's largest tributary is Río Claro, which enters the lake on the northern shore, followed by
Río Turbio on the lake's eastern end. The lake is drained on its western end by $11 \mathrm{~km}$ long Río Azopardo which discharges into the Seno Almirantazgo, a branch of the Magellan Strait.

Climatically, the Lago Fagnano region is situated in the cold temperate region (Rabassa et al. 2000) under the influence of the subantarctic west wind belt. The air temperature oscillates around $+5{ }^{\circ} \mathrm{C}$ with extreme readings of -20 and $+29{ }^{\circ} \mathrm{C}$ (1914-1960, Tuhkanen 1992). The precipitation is essentially of orographic nature, the mean annual precipitation in Ushuaia amounts to 550 $\mathrm{mm}$. During the austral winters, a persistent snow cover develops. The dominating wind directions are $\mathrm{W}$ or SW. The differentiated mountainous topography leads to a large meteorological variability on relatively small spatial and temporal scales. The drainage basin of the lake belongs to the vegetation zone of the subantarctic deciduous forest.

\section{METHODS}

In order to determine and analyze the lake-level variations in Lago Fagnano, tide gauge observations were performed simultaneously at up to three locations in the lake. Aanderaa WLR 7 pressure tide gauges were used (Aanderaa 2004). In order to ensure a stable sensor position throughout the observation periods, the pressure tide gauges were mounted in rugged mooring frames which were deployed on the lake floor in depths around $5 \mathrm{~m}$. The autonomously working instruments were repeatedly recovered for maintenance and replacement of batteries and data memory. In this way, tide gauge records of varying duration and a resolution ranging from $2 \mathrm{~min}$ to $1 \mathrm{~h}$ were retrieved. The tide gauge observations in Lago Fagnano were started in January 2003 at site B (Fig. 1b) situated on the southern 
Tab. 1. Lake-level records obtained at the locations A, B, and C in Lago Fagnano from pressure tide gauge registrations. The dates of the start and the end as well as the sampling interval (last column) are given for each record.

\begin{tabular}{cccc}
\hline A & B & C & Sampling interval \\
\hline & $28.1 .2003-13.2 .2003$ & & 5 min \\
& $13.2 .2003-05.2 .2004$ & & $60 \mathrm{~min}$ \\
$09.2 .2004-21.2 .2004$ & $05.2 .2004-23.2 .2004$ & $06.2 .2004-23.2 .2004$ & $2 \mathrm{~min}$ \\
$21.2 .2004-13.2 .2005$ & $23.2 .2004-06.2 .2005$ & $23.2 .2004-09.2 .2005$ & $15 \mathrm{~min}$ \\
& $06.2 .2005-03.2 .2006$ & & $10 \mathrm{~min}$ \\
& $03.2 .2006-19.5 .2006$ & & $10 \mathrm{~min}$ \\
\hline
\end{tabular}

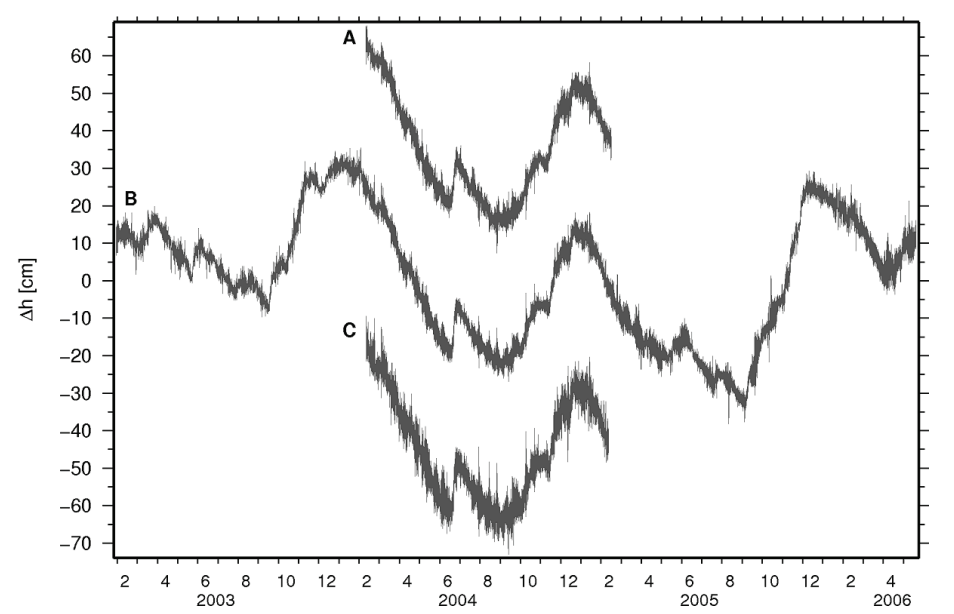

Fig. 2. Lake-level variations $\Delta \mathrm{h}$ recorded at the locations $\mathrm{A}, \mathrm{B}$, and $\mathrm{C}$ in Lago Fagnano. The time series of absolute lake-level heights derived from the pressure tide gauge records are reduced by their mean value; records $\mathrm{A}$ and $\mathrm{C}$ are offset for legibility.

lake shore $23 \mathrm{~km}$ from the eastern end. Between February 2004 and February 2005, two additional tide gauges were operated simultaneously at locations A, off a small cape in the NW lake part close to the Argentine-Chilean border, and $\mathrm{C}$ in a shallow bay $3 \mathrm{~km}$ from the eastern end of the lake. Since February 2005 the tide gauge measurements at site B have been continued with a data interval of $10 \mathrm{~min}$. The tide gauge records obtained in Lago Fagnano are listed in table 1.

A description of the applied algorithm of the lakelevel determination and a discussion of the measurement error budget of the used instrument type are given in Richter et al. (2005). The determination of lake-level heights from pressure tide gauge measurements requires not only the recorded total pressure at the sensor position but also the atmospheric pressure, the water density and the gravity. The time reference of the tide gauge measurements was corrected for a linear drift of the internal clocks of the tide gauges and data storage units. The pressure readings of the tide gauges represent mean values over an integration period of $40 \mathrm{~s}$ and are thus free of high-frequency variations. Along with the total pressure, the water temperature was recorded by the tide gauge at each measurement epoch. Based on that and applying the 1980 Equation of State for Sea Water (Millero \& Poisson 1981) the water density was derived. The gravity can be considered as a constant scaling factor throughout the observation period and was determined by the Gravity Formula 1980 (Moritz
1979). Air pressure data from the synoptic stations in Río Grande, Tolhuin and Ushuaia (Fig. 1a) were used to determine the atmospheric pressure variations at the tide gauge locations. For the interpolation of the barometer readings to the tide gauge locations, the spatial air pressure differences in the area under investigation were fitted by a plane. From these hourly values, the instantaneous local air pressure for each tide gauge measurement epoch was then obtained by linear interpolation in the time domain. For each measurement epoch, the observed total pressure was reduced by the interpolated air pressure and the remaining pressure difference was converted into the metric height of the water column above the pressure sensor applying the hydrostatic equation. The obtained relative height variations might be affected by datum shifts due to a sinking of the tide gauge moorings into the lake floor. GPS (Global Positioning System) observations on a floating buoy yielding the tide gauge reference height in a global reference frame for each deployment and recovery as well as the low-pass filtered difference time series between synchronous tide gauge readings were used to correct the obtained records for such systematic effects. In this way, time series of the local lake-level height at the observation sites were derived from the tide gauge records. The lake-level variation time series are displayed in figure 2 .

In the following analysis, the obtained lake-level series are regarded in statistical terms as realisations of 


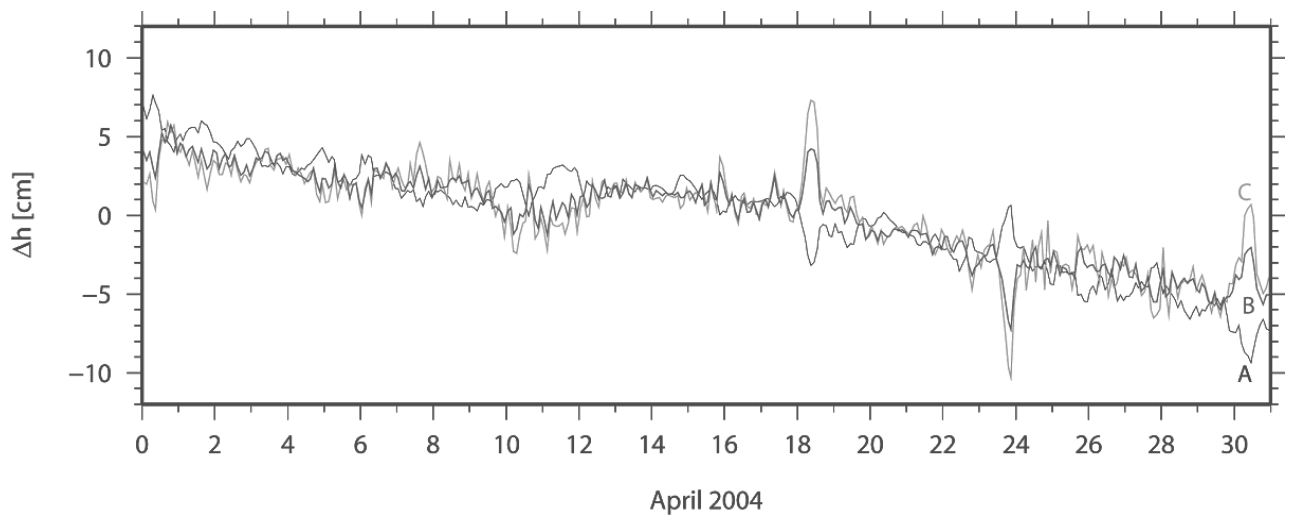

Fig. 3. Low-pass filtered ( $2 \mathrm{~h}$ means) lake-level variations $\Delta \mathrm{h}$ observed at the sites A, B, and C in Lago Fagnano in April 2004.

a stochastic process. Strictly, the available time series do not represent stationary stochastic processes since neither the conditions of stationarity nor those of ergodicity apply due to the presence of discrete persistent periods (lake tides). However, in order to facilitate the application of statistical tools, these conditions are established approximately by means of filtering. In order to quantify the accuracy of the lake-level determination, the auto-correlation function of the observed variations (measurement interval $2 \mathrm{~min}$ ) is employed. The random measurement error represented by the model of white noise is separated by subtracting an empirical, site-specific model of red noise that accounts for the real non-periodic lake-level changes. In this way we obtain standard deviations of stochastic measurement errors that vary among the three tide gauges between 2 and $3 \mathrm{~mm}$. Hence, the accuracy of a single tide gauge reading can be estimated to be $\pm 2.5 \mathrm{~mm}$. Since we restrict ourselves here to relative variations rather than the absolute height of the lake level, systematic error contributions can be neglected in this context.

\section{RESULTS}

\subsection{Intermediate-term lake-level changes}

The observed lake-level variations result from a superposition of signal components originating from different driving forces and mechanisms. These individual phenomena develop specific spatial patterns over the lake surface and act on different time scales. Lake-level observations at only one location do in general not allow to separate these contributions and to infer their spatial manifestation.

In this section we focus on lake-level signal components with typical periods of more than two hours. The lake-level variations observed in this part of the spectrum are explained to a great extent by two phenomena: a vertical shift of the water surface throughout the lake and a tilt of the lake level about a central nodal line.

A third remarkable phenomenon consists in the semi-diurnal and diurnal lake tides (Richter et al. 2009). Although the tidal amplitudes are relatively small (a few $\mathrm{mm}$ ), they produce a pronounced signature in the spec- trum due to their persistent, strongly periodical nature. Here the lake tides are not in the focus of interest. Therefore, their deterministic contribution is removed from the original lake-level signal. The determination of the shift and tilt of the lake level is based on time series of $2 \mathrm{~h}$ means of tide residuals inferred from the observed lake-level records.

As an example, the time series obtained for the three tide gauge sites throughout April 2004 are shown in figure 3. A common trend of lake-level drop is observed in all three records. The widespread distribution of the tide gauges over the lake allows to consider this coherent lake-level change as representative for the entire lake surface and thus to interpret it in terms of the lake-level shift. Over short periods, however, pronounced differences in the lake-level variations become evident among the three curves in figure 3 (see e.g., April 18 and 23). These short-term variations occur with systematically different amplitudes and directions at the three tide gauges: the largest variations are found at site $\mathrm{C}$, tide gauge $\mathrm{B}$ follows in the same sense but with reduced amplitude, whereas tide gauge A deviates into the opposite direction. These observations represent a lake-level tilt.

Over the entire period of simultaneous tide gauge measurement at the three sites, both the shift and the tilt of the lake level were extracted from the three low-pass filtered tide-reduced time series. Each time series was reduced by its mean value and the tide gauge locations were expressed in terms of their distance along the lake axis from a nodal line that bisects the lake surface area. Then, an absolute term reflecting the lake-level shift and a linear trend over the three sites representing the lakelevel tilt was estimated for each epoch.

\subsubsection{Lake-level Shift}

The lake-level shift as the uniform vertical displacement of the water surface all over the lake represents changes in the water volume contained in the lake. These water volume changes reflect variations in the relation between the total influx and total runoff. Any lake acts as a low-pass filter due to the retention effect. 

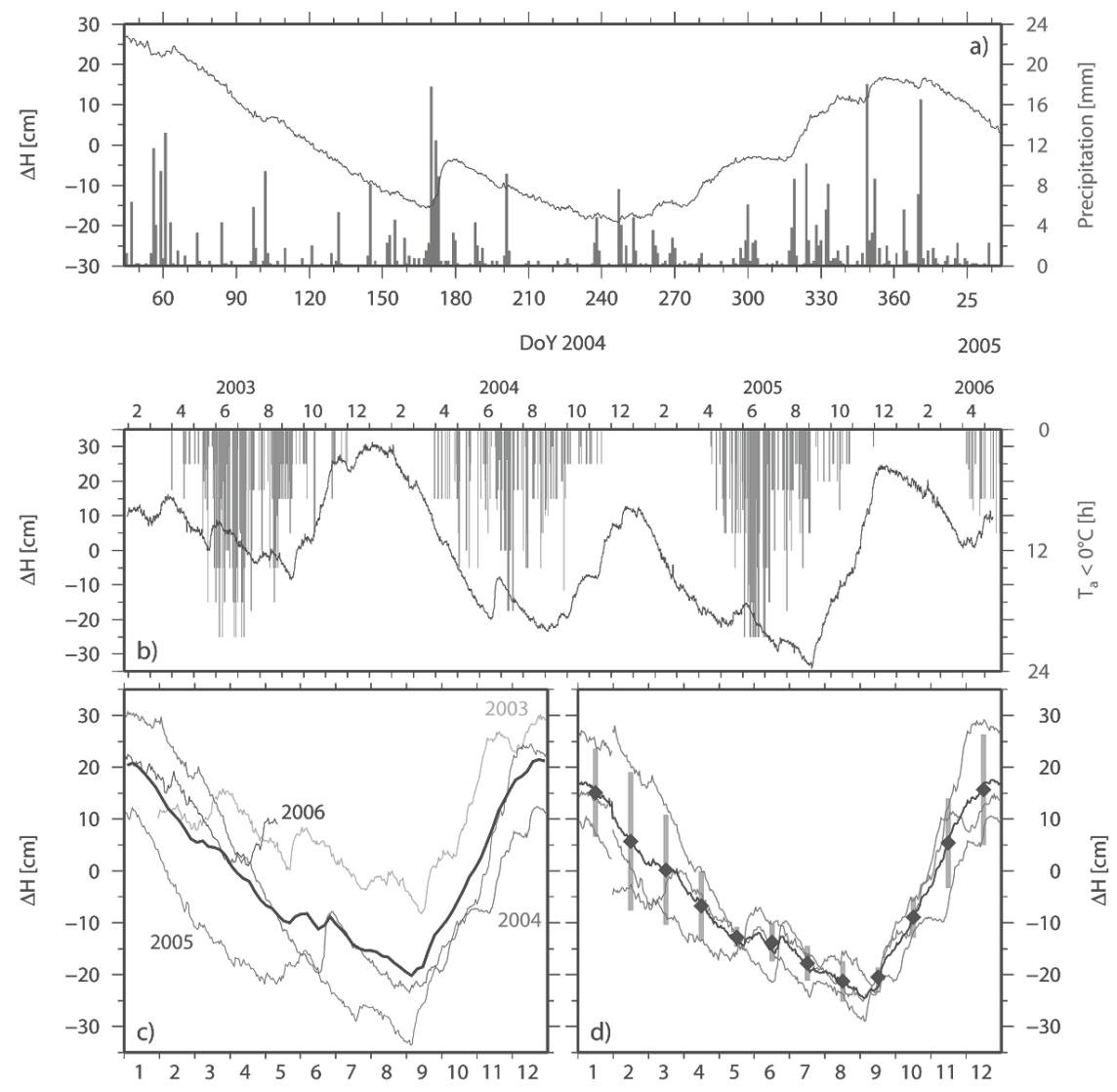

Fig. 4. a) Lake-level shift signal $\Delta H$ in Lago Fagnano throughout the simultaneous operation of three tide gauges (Feb $04-$ Feb 05 ). Grey bars show daily precipitations as recorded near site B (DoY: day of year). b) Lake-level shift signal $\triangle H$ in Lago Fagnano over the entire tide gauge observation period (Jan 03 - May 06). Grey bars indicate the daily number of hours below $0{ }^{\circ} \mathrm{C}$ as observed in Tolhuin. c) Lake-level shift signal $\Delta \mathrm{H} 2003$ - 2006 stacked from Jan (1) to Dec (12) and resulting mean signal (black curve). d) Stacked annual lake-level shift signal over three years (Feb 03 - Feb 06), each reduced by the corresponding annual mean value (grey lines), mean annual lake-level shift signal (black line), monthly mean values (diamonds) and standard deviations (grey bars) of the reduced lake-level shift signal.

The components of a lake's water budget are closely related to meteorological forcing variables. They therefore show a strong seasonal dependence and the lakelevel shift represents the predominating form of lakelevel variations on time scales exceeding a few days.

For the duration of the simultaneous operation of three tide gauges in Lago Fagnano, the lake-level shift was extracted as the common component in the lowpass filtered lake-level records. The resulting lake-level shift signal is shown in figure 4a. Over one year, a cyclic variation is observed with a lake-level maximum in austral summer and a minimum in late winter. Figure $4 \mathrm{~b}$ depicts the lake-level shift signal from February 2003 to May 2006. Here, the dominance of the annual cycle over a period of three years is illustrated. The stacked annual lake-level signal shown in figure $4 \mathrm{~d}$ reveals the general seasonal cycle. The mean annual signal has a maximum in December and a minimum in late August. The lake-level rise in austral spring occurs faster than the decrease in autumn. This is explained by the gradual accumulation of snow during the winter and its rapid release upon the warming in spring. The amplitude of the mean annual lake-level signal amounts to $21 \mathrm{~cm}$. Compared to other lakes (Lake Constance, central Europe: 1.5 m, Bäuerle et al. 1998; Lake Nyassa, East Africa: 12 m, Baumgartner 1996), Lago Fagnano shows a rather small seasonal variation range. This is explained in part by the relatively large ratio of approximately 1:5 between the surface area of the lake and its drainage basin. However, the seasonal range changes considerably among the years: in $2003(38 \mathrm{~cm})$ it reached only $66 \%$ of the range in $2005(58 \mathrm{~cm})$. Hence, the maximum observed annual range represents less than $1 \%$ of the total lake volume. In connection with the changes in the annual amplitudes, remarkable interannual variations of the lake level become evident (Fig. 4c). A maximum difference of more than $30 \mathrm{~cm}$ is observed for the comparison of the lake levels in late August 2003 and 2005.

The annual lake-level shift signal is in phase with the seasonal air temperature variation observed at the meteorological station in Tolhuin. This is shown in figure $4 \mathrm{~b}$ in terms of the daily durations of freezing temperature. The lake water temperature signal in $5 \mathrm{~m}$ depth 

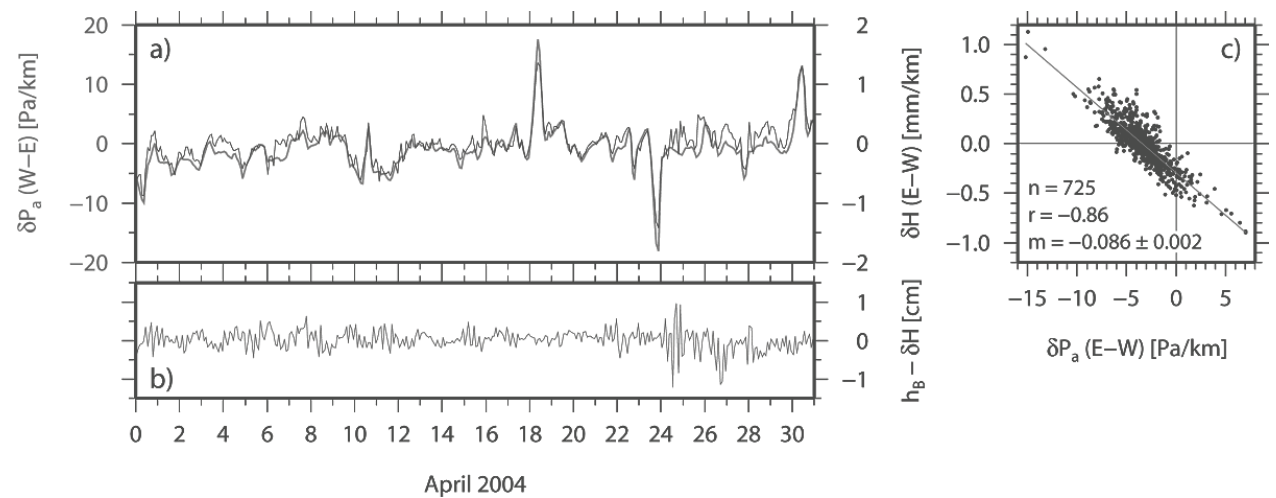

Fig. 5. a) Lake-level tilt signal $\delta \mathrm{H}$ in Lago Fagnano (black) and air pressure gradient $\delta \mathrm{P}$ (grey, note reversed sense) over the lake in April 2004. b) Deviation of the low-pass filtered (2 h means) lake-level variations observed at site B from the linear (shift and tilt) lake-level model over the same period $\left(\mathrm{h}_{\mathrm{B}}-\delta \mathrm{H}\right)$. c) Linear regression of the E-W air pressure gradient $\delta \mathrm{P}$ with the lake-level tilt $\delta \mathrm{H}$ throughout the simultaneous operation of three tide gauges (Feb 04 - Feb 05). Regression line with slope $\mathrm{m}$ is shown in grey; $\mathrm{n}$ is the number of points, $\mathrm{r}$ is the normalised correlation coefficient.

recorded by the tide gauge at location $\mathrm{B}$ varies between 4 and $12{ }^{\circ} \mathrm{C}$ and follows the seasonal air temperature variation with a delay between a half (temperature maximum) and two (temperature minimum) months. The temperature increase in the epilimnion produces a lake-level increase in summer due to thermal expansion (steric effect), which amounts to less than $5 \%$ of the observed seasonal lake-level signal.

Figure $4 \mathrm{a}$ shows that events involving a rapid, intensive rise in lake level followed by a more gradual decrease are superimposed on the annual signal. These short-term changes reach ranges of $12 \mathrm{~cm}$ (June 2004, day of year 170-180). They often correlate with the daily precipitation sums measured near the tide gauge site $\mathrm{B}$, which are included in figure $4 \mathrm{a}$ (additional, less pronounced events around days of year 63, 350, 370).

\subsubsection{Lake-level Tilt}

The rigid tilt of a lake level about a central nodal line was termed by Forel (1895) as denivellation and explained as a result of wind action. Atmospheric pressure gradients over the lake may produce a similar reaction, which is described by the differential inverse barometer (IB) effect (e.g., Wunsch \& Stammer 1997). The resulting tilt of the lake level represents in both cases a quasi-static response. Generally, its variation in time follows that of the driving force. However, a minimum forcing duration is required in order to produce a significant lake-level response.

Figure 5a shows the lake-level tilt of Lago Fagnano during April 2004 as inferred from the three tide gauge records. The residuals at tide gauge site $\mathrm{B}$ resulting from the combined adjustment of the lake-level shift and tilt are plotted in figure $5 \mathrm{~b}$. These residuals reflect both measurement noise and deviations from the model of a rigid lake surface. The residual time series resembles random noise. Its standard deviation amounts to $2 \mathrm{~mm}$ and is one order of magnitude less than the lake-level tilt signal at this location close to the nodal line. This confirms that the lake-level variations with periods exceeding two hours can be attributed largely to a combination of shift and tilt of the lake level.

In order to investigate the interaction of the lakelevel tilt with the atmospheric forcing the time series of the regional air pressure gradient in $\mathrm{W}-\mathrm{E}$ direction was derived from the air pressure records of the meteorological stations in Río Grande, Tolhuin and Ushuaia. In figure $5 \mathrm{a}$, the filtered ( $12 \mathrm{~h}$ means) variation of the air pressure gradient is shown together with the lake-level tilt. Both signals show a very similar behaviour. This observation leads to the conclusion that the lake-level tilt in Lago Fagnano is essentially driven by the variation of atmospheric pressure gradients according to the model of the differential IB effect over the lake.

Figure 5c shows the result of a linear regression of the lake-level tilt and the E-W air pressure gradient. Both time series were smoothed ( $12 \mathrm{~h}$ means) because the pressure gradient variations of shorter periods, originating to a large part from noise of the measurements and gradient determination, show a random character and do not correlate with the observed lake-level tilt. The obtained correlation coefficient $r=0.86$ (725 points) proves the close relation between both processes. The determined regression, however, does not run through the coordinate origin. This is explained by a permanent E-W air pressure gradient in the region under investigation. According to the air pressure data for a four years observation period, this permanent gradient amounts to $3.4 \mathrm{~Pa} \mathrm{~km}^{-1}$. This, in turn, implies a deviation of the long-term mean lake level from an equipotential surface of the gravity field in the order of $0.3 \mathrm{~mm}$ $\mathrm{km}^{-1}$. The obtained regression factor amounts to $m=$ $0.086 \mathrm{~mm} \mathrm{~Pa}^{-1}$. An ideal inverse barometer would yield a factor of approximately $0.1 \mathrm{~mm} \mathrm{~Pa}^{-1}$. Thus the lake level of Lago Fagnano fulfils the model of the differential IB effect to $85 \%$.

The most likely explanation for the lake-level tilt damping of $15 \%$ with respect to the theoretical effect consists in the impact of the wind. Atmospheric pres- 


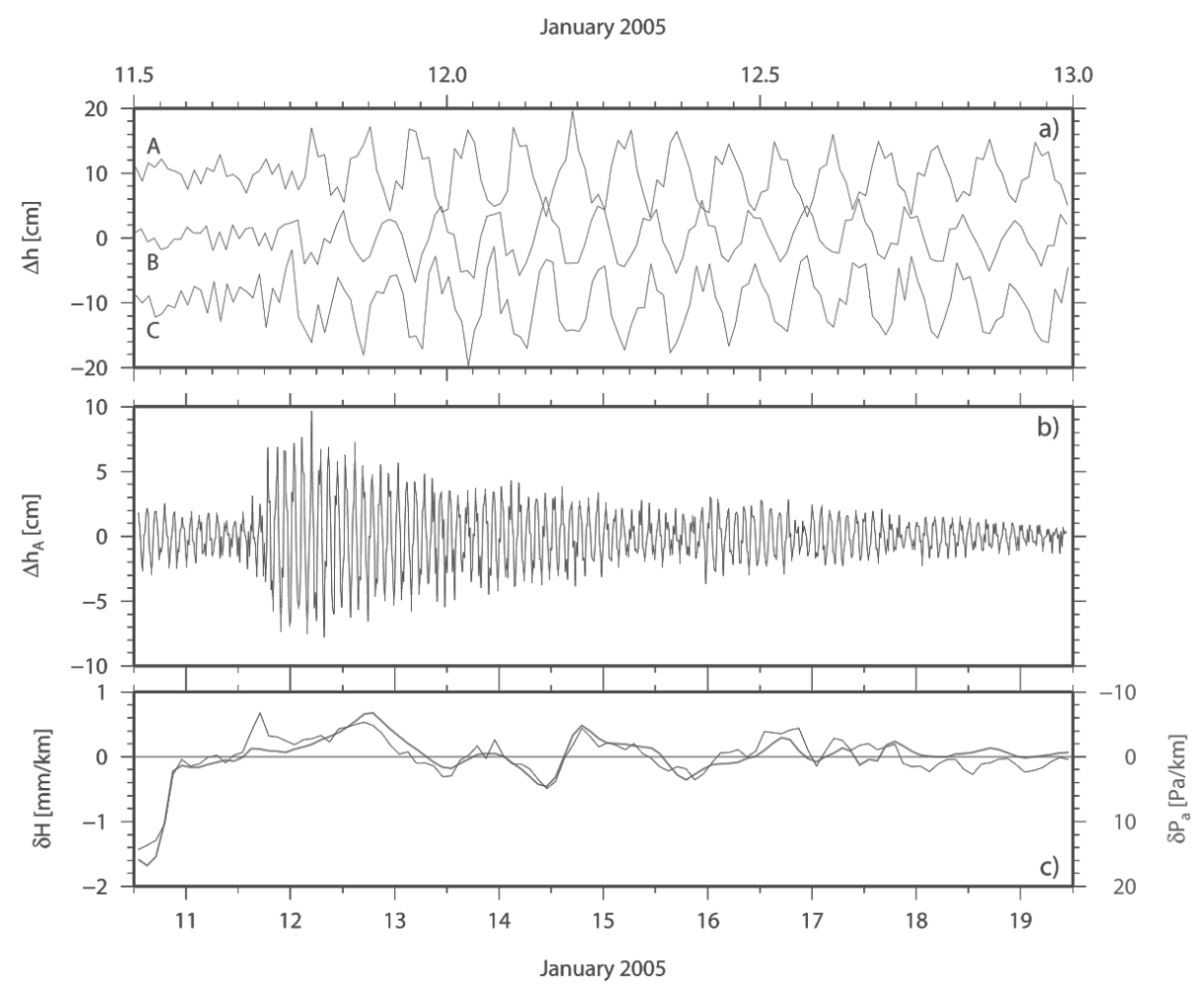

Fig. 6. a) Lake-level signal $\Delta \mathrm{h}$ over $1.5 \mathrm{~d}$ as recorded by the three tide gauges $\mathrm{A}, \mathrm{B}$, and $\mathrm{C}$ in Lago Fagnano demonstrating the onset and development of surface seiches with a period of $2 \mathrm{~h}$. b) High-pass filtered ( $2 \mathrm{~h}$ cutoff) lake-level signal at site $\mathrm{A} \Delta \mathrm{h}_{\mathrm{A}}$ over $9 \mathrm{~d}$ for the same seiches series. c) Variations in lake-level tilt $\delta \mathrm{H}$ (black) and W-E air pressure gradient $\delta \mathrm{P}$ (grey) for the same period.

sure gradients and wind intensity are closely related, but the directions of their maximum effects often differ. Especially in view of the channel-like topography of the Lago Fagnano valley, an effective wind component acting in opposite direction than the pressure gradient does not seem unusual. Finally, the fact that most descriptions of this form of lake-level variation in the literature are based on the impact of the wind suggests that also in the case of Lago Fagnano the wind plays an important role in the generation of lake-level tilts.

As a potential alternative explanation for the damping of the lake-level tilt, the impact of the atmospheric pressure loading was considered. The spatial air pressure patterns produce a response of the elastic earth involving deformations of both the earth crust and the equipotential surfaces of the gravity field (Van Dam et al. 2002). Since air pressure variations over the oceans are compensated by the IB effect, essentially the pressure differences over the continents are effective. The produced crustal deformation indeed reduces the relative tilt between the solid earth surface and the lake level, which is measured by pressure tide gauges on the lake floor. This crustal effect, however, is partly reduced by the associated gravitational effect. Numeric modelling of the atmospheric loading effects in the Lago Fagnano region does not exceed $\pm 0.06 \mathrm{~mm}$ over $100 \mathrm{~km}$ and is thus two orders of magnitude too small to explain the deviation of the lake-level tilt from the IB model.
The maximum lake-level tilt observed by three tide gauges amounts to $1.57 \mathrm{~mm} \mathrm{~km}^{-1}$ corresponding to a lake-level rise of $8.2 \mathrm{~cm}$ at the western lake end. The strong correlation between lake-level tilt and air pressure gradient now allows the separation of shift and tilt in the lake-level variations from only one site in the lake. Based on the determined linear relation and the air pressure data from the three meteorological stations, the lake-level tilt and shift was extracted for the periods of tide gauge operation at site B only. In this way, the lakelevel shift signal presented in figures $4 b-d$ was obtained. The maximum E-W air pressure gradient over the lake registered throughout the entire tide gauge operation amounts to $3.67 \mathrm{~Pa} \mathrm{~km}^{-1}$, producing a lakelevel change of $16.6 \mathrm{~cm}$ at the eastern and western lake shores.

\subsection{Short-period lake-level oscillations: surface seiches}

In figure $6 a$ the lake-level variations recorded at the three tide gauges during one day and a half are depicted. They illustrate in a nearly ideal manner the phenomenon of surface seiches as it was described by Forel (1895): All three time series exhibit a pronounced periodic oscillation with exactly the same period of $2 \mathrm{~h}$. Among the tide gauges, the amplitudes increase with their distance from the lake centre, very similar to the lake-level tilt, and an opposite variation sense at the western (lo- 


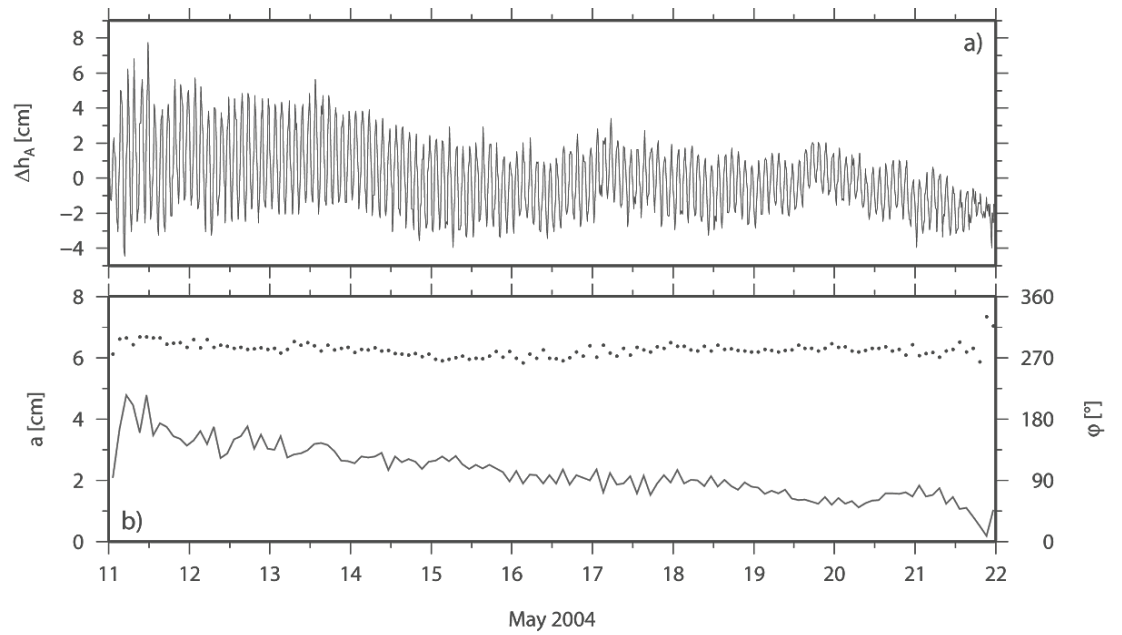

Fig. 7. Undisturbed series of surface seiches in Lago Fagnano lasting $11 \mathrm{~d}$. a) Lake-level signal $\Delta \mathrm{h}_{\mathrm{A}}$ as observed at site $\mathrm{A}$. b) Amplitude a (grey line) and phase angle $\varphi$ (dots) of the harmonic signal with $2 \mathrm{~h}$ fundamental period.

cation A) compared to the eastern part of the lake is revealed. This is the signature of a uninodal standing wave. When comparing the observed amplitudes reaching the order of $1 \mathrm{dm}$ with the magnitudes of the previously discussed phenomena, the considerable relative importance of this type of lake-level variations for Lago Fagnano becomes evident.

The precondition for surface seiches to evolve is a sudden disturbance of the equilibrium between the gravity and other external forces (Hutchinson 1957). In figure $6 \mathrm{~b}$, the evolution of the same seiches event as recorded at site $\mathrm{A}$ is shown over 9 days along with the changes in W-E air pressure gradient and lake-level tilt (Fig. 6c). The seiches series is preceded by a sharp change in both pressure gradient and surface tilt. However, this event takes place half a day before the onset of the oscillation. When the oscillation amplitude starts to rise, there occurs another rapid lake-level tilting but no appreciable change in the pressure gradient. Hence, the most likely excitation force are winds, which were not able to produce a large, persistent lake-level tilt but, probably due to their near-resonant timing, were effective to initiate the long-lasting oscillation of the water body. Upon excitation, the seiches amplitude rises rapidly: within five cycles the maximum amplitude is reached. Afterwards the oscillation continues for more than seven days with slowly decreasing amplitude. Closer inspection reveals a slight revitalisation of the oscillation on late January 15 , however with shifted phase, which is accompanied by peaks in air pressure gradient and lake-level tilt. Considering the long oscillation durations and the high meteorological variability in the region, a cut of the undisturbed oscillation by a further excitation impulse with usually different phase appears to be a common form of terminating seiches series in this lake.

Lago Fagnano can indeed be regarded as unique with respect to the perpetuation duration of surface seiches. Figure $7 \mathrm{a}$ displays the original, unfiltered lake- level variations recorded at site A during eleven days. Throughout this period, an undisturbed seiches series of 143 cycles of $2 \mathrm{~h}$ was observed. This is proven by the constant phase angles and the smooth, monotonous decay of the amplitude throughout the time section (Fig. $7 b$ ). The presented series exceeds that reported by Forel (1895) from Lake Geneva (7 d $17 \mathrm{~h}$ ), which is recognised by Hutchinson (1957) as the longest continuous seiches record existing. The ability of a lake to sustain resonant oscillations of its water body depends essentially on the influence of dissipative friction and thus on the geometric dimensions and bathymetry of the basin. As a quantitative indicator for this lake-specific property, Neumann (1941) used the logarithmic decrement:

$$
\lambda=\frac{\ln a_{n}-\ln a_{m}}{m-n}
$$

with $a_{n}, a_{m}$ being the amplitudes of the $n$-th and $m$-th oscillation cycles, respectively. Here, an exponential decrease of the seiches amplitude with time is considered and the parameter $\lambda$ describes the rate of this decrease. The seiches series shown in figure 7 yields $\lambda=$ 0.018 for Lago Fagnano. The comparison with the corresponding value for Forel's study object Lake Geneva of 0.030 (Neumann 1941) emphasises the very low level of oscillation damping in Lago Fagnano. (For the strongly damped Baltic Sea, Neumann obtained $\lambda=$ $0.50)$.

In his description of the surface seiches in Lake Geneva, Forel (1895) restricted himself largely to the fundamental, uninodal seiches mode. Figure 6a shows, however, that the dominant oscillations with $2 \mathrm{~h}$ period in Lago Fagnano are preceded and superimposed by additional periodic signals of shorter cycle length. The spectral analysis provides a valuable means to decompose such a mixed periodic signal. Figure 8 shows the amplitude spectra of the lake-level variations observed simultaneously by the three tide gauges with an interval of 2 min over twelve days. In all cases, a steep general 


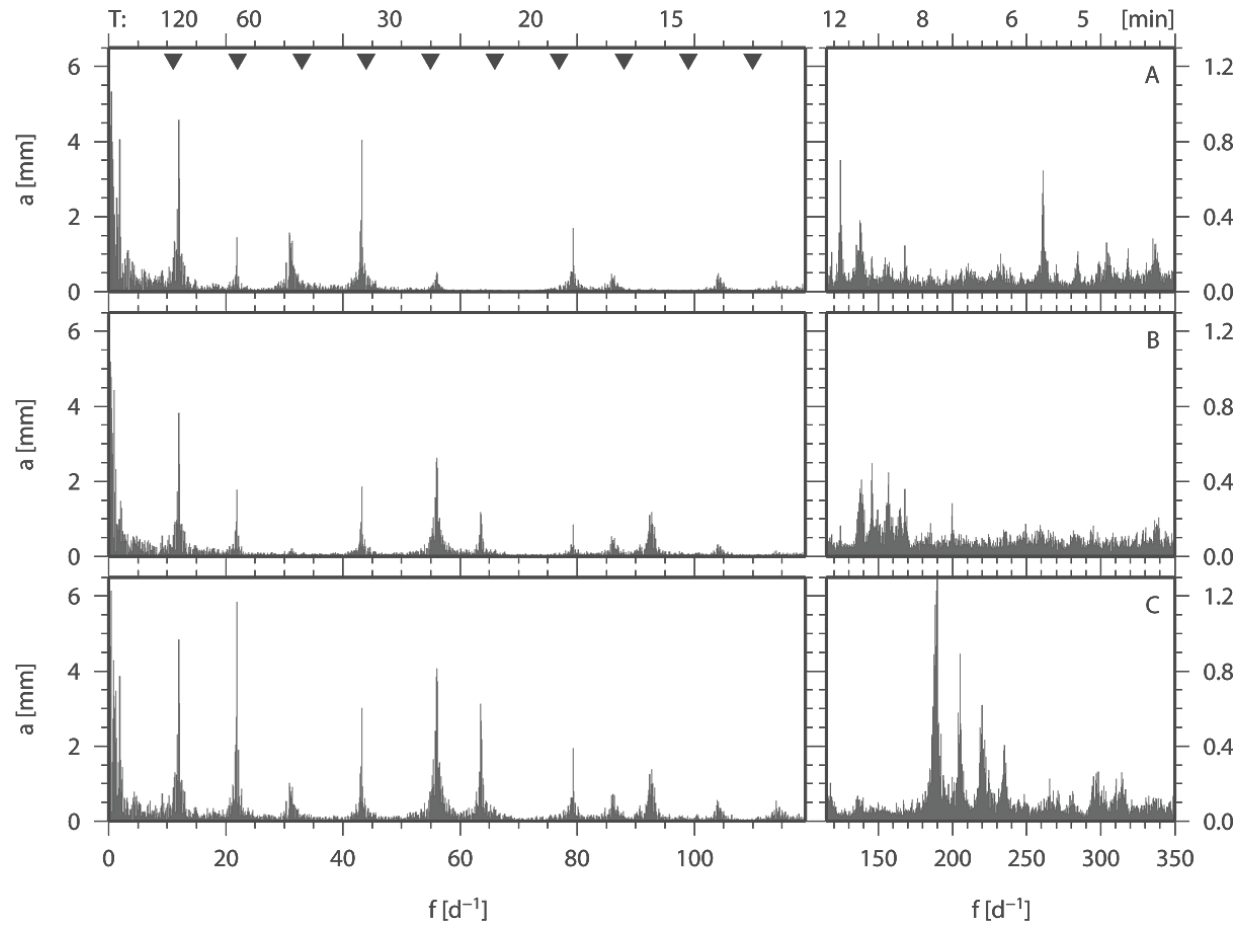

Fig. 8. Amplitude spectra of the lake-level variations recorded at the three tide gauge sites A, B, and C in Lago Fagnano with sampling interval 2 min over $12 \mathrm{~d}$ in Feb 04 . For each frequency $\mathrm{f}\left(\mathrm{d}^{-1}\right.$ : cycles per day) the corresponding amplitude a is displayed. Estimated stochastic measurement errors correspond to a constant amplitude of $0.08 \mathrm{~mm}$. Triangles on top indicate the theoretical frequencies for the surface seiches modes 1 through 10 according to Merian's formula for basin length $104 \mathrm{~km}$ and depth $70 \mathrm{~m}$. On the right, an enlarged display of the amplitude spectrum for high frequencies is shown (note different scaling of both frequency and amplitude). For comparison, the periods T corresponding to selected frequencies are given on top.

Tab. 2. Surface seiches modes observed in Lago Fagnano. For modes 1 through 11, the period $T$, frequency $f$ and the amplitudes $a$ and phase angles $\varphi$ (resulting from the Fourier transformation of lake-level observations with sampling interval 2 min over $12 \mathrm{~d}$ in Feb 04) at the three tide gauge sites A, B, and C are given.

\begin{tabular}{|c|c|c|c|c|c|c|c|c|}
\hline \multirow[b]{2}{*}{ Mode } & \multirow[b]{2}{*}{$T[\mathrm{~min}]$} & \multirow[b]{2}{*}{$f\left[\mathrm{~d}^{-1}\right]$} & \multicolumn{2}{|c|}{ A } & \multicolumn{2}{|c|}{ B } & \multicolumn{2}{|c|}{$\mathrm{C}$} \\
\hline & & & $a[\mathrm{~mm}]$ & $\varphi\left[^{\circ}\right]$ & $a[\mathrm{~mm}]$ & $\varphi\left[^{\circ}\right]$ & $a[\mathrm{~mm}]$ & $\varphi\left[^{\circ}\right]$ \\
\hline 1 & 120.0 & 12 & 4.57 & 149 & 3.83 & 328 & 4.88 & 329 \\
\hline 2 & 65.7 & 22 & 1.44 & 169 & 1.78 & 167 & 5.85 & 171 \\
\hline 3 & 46.6 & 31 & 1.57 & 241 & 0.15 & 57 & 1.02 & 239 \\
\hline 4 & 33.3 & 43 & 4.04 & 81 & 1.86 & 83 & 3.03 & 263 \\
\hline 5 & 25.7 & 56 & 0.53 & 258 & 2.64 & 79 & 4.08 & 260 \\
\hline 6 & 22.7 & 63 & 0.08 & 219 & 1.17 & 261 & 3.13 & 80 \\
\hline 7 & 18.2 & 79 & 1.71 & 5 & 0.83 & 185 & 1.94 & 184 \\
\hline 8 & 16.7 & 86 & 0.37 & 178 & 0.44 & 174 & 0.73 & 170 \\
\hline 9 & 15.5 & 93 & 0.09 & 14 & 1.18 & 17 & 1.39 & 14 \\
\hline 10 & 13.9 & 104 & 0.42 & 132 & 0.30 & 307 & 0.57 & 307 \\
\hline 11 & 12.6 & 114 & 0.28 & 238 & 0.17 & 16 & 0.55 & 211 \\
\hline
\end{tabular}

amplitude drop to below $0.1 \mathrm{~mm}$ within a few tens of cycles per day $\left(\mathrm{d}^{-1}\right)$ is observed. Superimposed there appear pronounced, discrete amplitude peaks of several $\mathrm{mm}$ which occur at identical frequencies in all three spectra. These represent the different modes of surface seiches in Lago Fagnano. The low, constant background level indicates the rather negligible importance as well as the random nature of other contributions to the lakelevel variations in this short-period part of the spectrum.

The most remarkable amplitude peak is located at a frequency of $12 \mathrm{~d}^{-1}$ and represents the fundamental sur- face seiches mode $n=1$ in Lago Fagnano with $2 \mathrm{~h}$ period. In almost equidistant frequency increments, ten further peaks are distinguished clearly in the three records. These are the manifestation of the longitudinal surface seiches modes $n=2-11$, each of which represents a standing wave with $n$ nodes.

The amplitudes and phases obtained at these frequencies are given in table 2 . The absolute amplitudes and phases depend on the excitation of the individual seiches series. Among the three observation sites, the determined amplitudes vary considerably, but the rela- 
tive phase differences are always close to $0^{\circ}$ or $180^{\circ}$. This means, that these lake-level variations occur synchronously at the three locations, but with opposite sign in the case of a $180^{\circ}$ phase shift. Both the phase reversal and amplitude differences are determined by the relative location of the tide gauges with respect to the nodes of the standing waves. Their period lengths, and thus their frequencies, however, depend only on the basin geometry of the lake. By applying Merian's formula (e.g., Mortimer 1974) to the known length and mean depth of Lago Fagnano, approximate theoretical period lengths were calculated. They are included in figure 8 .

The surface seiches appear as narrow frequency bands in figure 8 which decrease rapidly at both sides. In statistical terms, this is the spectral signature of quasi-persistent periods. They reflect the fact that the signal has indeed a constant period but experiences phase shifts and amplitude changes with time. In the interpretation of the obtained spectra (Fig. 8, Tab. 2) attention must be paid to inherent sample effects such as aliasing and power leakage (e.g., Bloomfield 1976). Nevertheless, these effects can be assumed to affect all three lake-level records in a similar way and, therefore, not to substantially affect the relative amplitude and phase relations between the tide gauges.

The identified eleven surface seiches modes do not exhaust the rhythmical oscillations detectable in the lake-level spectra from Lago Fagnano. Also at frequencies exceeding that of the mode 11 , several signatures of quasi-persistent periods with amplitudes of up to $3 \mathrm{~mm}$ are found in the three spectra (Fig. 8, right). These might represent even higher longitudinal surface seiches modes, increasing their number to more than 20 . Their regular spectral distribution in frequency steps within the range of those between modes 1-11 would support this interpretation. However, these signal components encountered in the spectrum of one of the tide gauges lack significant counterparts in the other records; and we regard the spectral coincidence of significant amplitudes in at least two spectra as condition for an unambiguous identification as longitudinal surface seiches. As an alternative explanation, transversal seiches modes could be considered. In fact, the largest of these amplitudes of $3.3 \mathrm{~mm}$ at site $\mathrm{C}$ occurs with a period of 7.6 min, comparable to what Merian's formula predicts for a standing wave across the lake axis at this location. The high variability along the lake axis in both cross section geometry and forcing conditions could be responsible for the differing frequency between the tide gauge locations. The clustering of spectral peaks into equidistant series, however, cannot be explained by transversal seiches.

The spatial pattern of the surface seiches in Lago Fagnano is visualised in figure 9. There, for the first six identified longitudinal modes, the normalised amplitudes as obtained from the Fourier transformation for the three tide gauge locations are plotted over the lake axis length. Wave profiles that represent the standing waves for the simple model of a long, non-rotating channel are included for comparison.

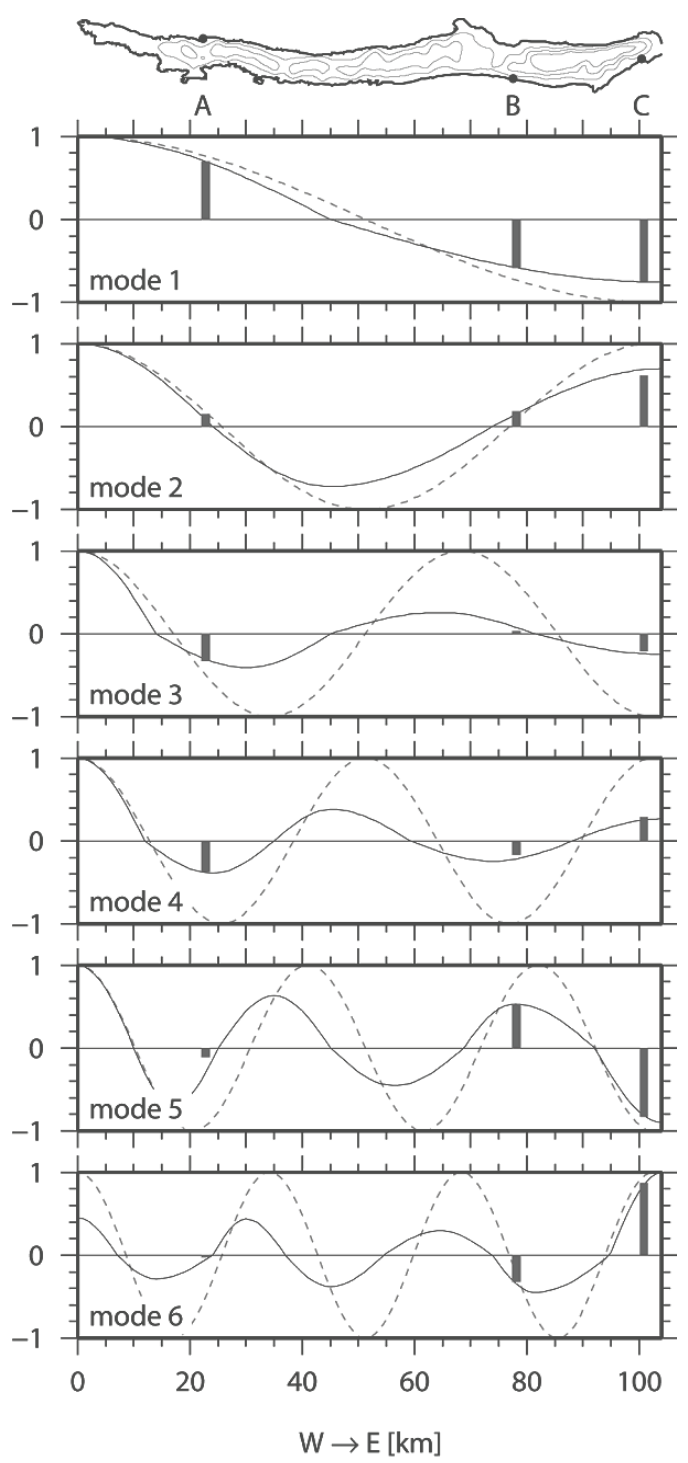

Fig. 9. Amplitude profiles of the surface seiches modes 1-6 in Lago Fagnano. Over the distance along the lake axis from $\mathrm{W}$ to $\mathrm{E}$, modelled normalised amplitudes according to the simple channel model (dashed) and a model accounting for the lake basin geometry (solid lines) are shown. The relations between the amplitudes resulting from a Fourier transformation of the lake-level variations recorded at the three tide gauge sites $\mathrm{A}$, $\mathrm{B}$, and $\mathrm{C}$ with sampling interval 2 min over $12 \mathrm{~d}$ in Feb 04 are indicated by bars at their respective locations. Negative amplitudes represent a relative phase shift of $180^{\circ}$.

Their general agreement with the observed amplitude and phase relations confirms the attribution of the signal components to the seiches modes. It proves furthermore that the one-dimensional channel model approximates quite effectively the hydrodynamics in Lago Fagnano. More complex models such as Kelvin or Poincaré waves (Mortimer 1974), which take the impact 
Tab. 3. Summary of the principal mechanisms affecting the lake level of Lago Fagnano. For each phenomenon, a typical maximum amplitude $a$, typical periods, and the identified driving agents are given in a generalizing manner.

\begin{tabular}{ccccc}
\hline Mechanism & $a[\mathrm{~cm}]$ & Period & Primary forcing & Secondary forcing \\
\hline lake-level shift & 25 & 1 year, (events: several days) & hydrologic run-off & precipitation (events) \\
lake-level tilt & 15 & a few days & air pressure & wind \\
surface seiches & 10 & 2 hours & wind & air pressure \\
lake tides & 0.5 & 12,24 hours & ocean tidal loading & moon, sun (direct tidal potential) \\
\hline
\end{tabular}

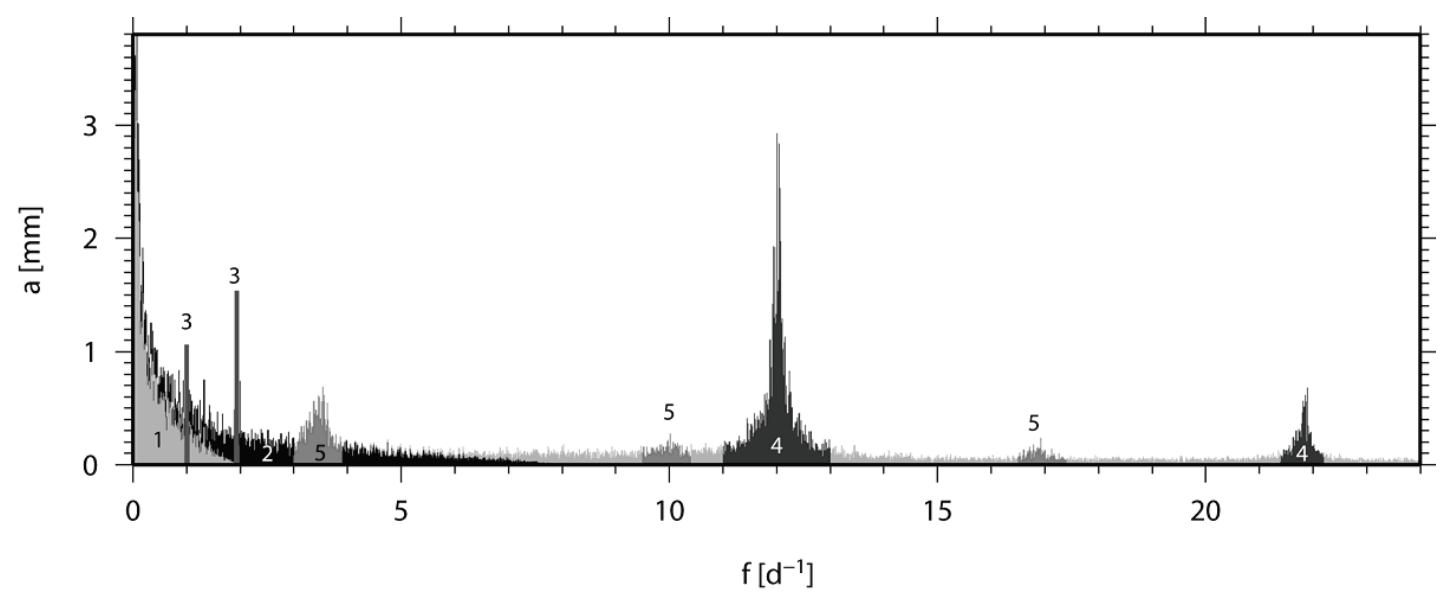

Fig. 10. Amplitude spectrum of the lake-level signal recorded at site B in Lago Fagnano with sampling interval 15 min Feb $04-$ Feb 05. The contributions of lake-level shift (1), lake-level tilt (2), lake tides (3), and surface seiches (4) incl. their alias signatures (5) are indicated schematically.

of the earth rotation on large lakes into account, are not relevant for standing surface waves in this lake, because it is too narrow compared to a Rossby radius of $220 \mathrm{~km}$.

An improvement of the spatial seiches model requires the actual basin geometry of the lake to be taken into account. A westward shift of most of the wave nodes, for example, would lead to a better agreement with the observed amplitude ratios. The location of nodes and antinodes is determined by the propagation velocity of the standing wave which in turn depends on the basin depth. Thus the bathymetry controls the distribution of the nodes, while the varying lake width results in a differentiated amplitude scaling among the wave cells. Four physically motivated requirements were formulated for an improvement of the standing wave profiles, namely:

1. the distance between a node and the neighbouring antinode equals the distance the standing wave travels in a quarter of the seiches period;

2. the lake depth and thus wave propagation velocity are independent from the seiches mode, implying that the nodes collocate with nodes/antinodes in certain higher modes;

3 . the mass of the shifting lake water must be conserved within the two wave cells to either sides of a node, accounting for an asymmetric node spacing and a non-uniform basin width;

4. the wave profiles must be continuous.
Based on these requirements, the bathymetric model of the lake, its shoreline geometry, and the observed seiches periods were inverted yielding improved amplitude profile models for the first six surface seiches modes. The obtained amplitude profiles are included in figure 9. Indeed they exhibit a far better agreement with the observed amplitude ratios. The westward shift of the nodes with respect to the simple channel model arises from the larger water depth in the eastern part of the lake, and the increase in amplitude towards the western and eastern shores corresponds with the narrowing of the basin cross-section. In the eastern part of the lake, where the bathymetric model relies on sufficient echosounding data, the node locations for all six modes were obtained from a common adjustment. In the western part of the lake, however, lake depth measurements are sparse. Here the observed amplitude/phase relations and periods of the surface seiches were used to provide constraints for the effective water depth. Hence, in a certain sense, the superficial observation of a lake level may help to get to the bottom of the water body.

\section{DISCUSSION AND SYNTHESIS}

The main characteristics of the three forms of lakelevel variations treated in the previous sections - shift and tilt of the lake level and surface seiches - are summarised in table 3. In figure 10, their contributions to the observed lake-level variations in Lago Fagnano are visualised schematically in a section of an amplitude 
spectrum. Here it becomes evident that the observed lake-level variations are explained to a very large extent by the three examined phenomena plus the lake tides.

The remaining portions of the spectrum show amplitudes largely close to the significance level (0.04 $\mathrm{mm}$ in Fig. 10) and resemble the signature of random variations. They most likely represent quasi-static responses of the lake level to wind forcing. In accordance with the forcing field, these lake-level variations extend over a wide range of frequencies and are characterised by their stochastic occurrence and extension in space and time. Their identification, characterisation and relation to the forcing would require representative data of the wind field over the lake surface.

Since the secondary phenomena affecting the lake level, including wind swell, do not produce an appreciable manifestation in the spectrum they may be neglected in a description of the lake-level variations over extended time scales. Thus a model of the lake-level variations in Lago Fagnano may be restricted to the phenomena listed in table 3. Each of them has been separated and characterised in space, time, causes and mechanism. In principle, the lake level in any point of the lake at any time can be predicted by superposition of the four contributions for each of which a description of the forcing is required and an appropriate transfer function is applied. This is straightforward for the air-pressure driven lake-level tilt and the strongly deterministic tides. The modelling of the surface seiches and lakelevel shift, however, would require wind data over the lake and parameters of precipitation and hydrologic runoff over the lake's drainage basin, respectively, which are not available at present. As an alternative, the lakelevel variations in one point within the lake can be regarded as a representation of the integral effects of these driving forces. Based on the found principles, spatial patterns and spectral signatures, the individual phenomena can be separated and then, by means of transfer functions, extrapolated to any point in the lake. On this basis, a lake-level transfer model was developed for Lago Fagnano. It allows the transfer of lake-level variations observed at tide gauge site $\mathrm{B}$ to site $\mathrm{C}$ with a standard deviation of $10 \mathrm{~mm}$ with respect to the recorded signal at $\mathrm{C}$ (over $4.5 \mathrm{~d}$ ). This deviation is composed of random measurement errors of both tide gauges as well as lake-level variations not considered by our modelling approach (i.e., local, short-term wind response). The model was applied successfully to reduce short-term geodetic lake surface observations to a mean lake level using only one synchronous tide gauge record (Del Cogliano et al. 2007).

\section{CONCLUSIONS}

Based on tide gauge records at three locations, a thorough picture of the lake-level variations in Lago Fagnano is drawn. Three force-response mechanisms are shown to govern essentially the lake level. The lake- level shift reflecting the water mass exchange with the environment predominates the long-term variations with a pronounced seasonal cycle. The lake-level tilt represents the quasi-static response to atmospheric pressure gradients fulfilling the IB model to $85 \%$. The surface seiches are exceptionally well pronounced with at least eleven detected longitudinal modes with a fundamental period of $2 \mathrm{~h}$.

An undisturbed surface seiches series over eleven days was recorded in Lago Fagnano which exceeds those reported for any other lake. This is evidence for an unusually low dissipative friction. The lake's distinct basin geometry is therefore well reflected by simple models. This fact, together with the generally low lakelevel variability, makes Lago Fagnano exceptionally well suited for hydrodynamic studies, including also internal circulation processes.

The analysis of the separated components of the lake-level signal led to their relations to driving forces. A lake-specific transfer function of the response to air pressure changes was determined empirically. A spatial amplitude transfer model for surface seiches was developed involving an inversion of surface seiches observations to constrain the insufficiently known bathymetry. These transfer functions were combined to an operational model that allows to transfer lake-level variations at one reference point to any other location in the lake with an accuracy in the order of $1 \mathrm{~cm}$.

The results presented here will hopefully contribute to the understanding of the hydrodynamics in Lago Fagnano. However, a number of questions have been risen that call for further investigation. For example, representative wind measurements would allow an important improvement in the description of the lakelevel variations. In particular, the remarkable deviation of the lake-level tilt from an ideal inverse barometer might be explained.

\section{ACKNOWLEDGEMENTS}

We thank the team of Prefectura Naval Argentina, Destacamiento Lago Fagnano for the support in the field work and Rodolfo Iturraspe from Centro Austral de Investigaciones Científicas / Dirección de Recursos Hídricos de Tierra del Fuego for the provision of precipitation data at site B. The meteorological data at Río Grande, Tolhuin and Ushuaia were provided by Servicio Meteorológico Nacional de Argentina. The field work was funded partly by IB/BMBF, Germany and SECyT, Argentina.

\section{REFERENCES}

Aanderaa Instruments. 2004. Operating manual WLR $7 \& 8$. Aanderaa Instruments, Technical description no. 175.

Bäuerle, E., D., Ollinger \& J. Ilmberger. 1998. Some meteorological, hydrological, and hydrodynamical aspects of Upper Lake Constance. Arch. Hydrobiol. Spec. Issues Advanc. Limnol., 53: 31-83. 
Baumgartner, A. 1996. Lehrbuch der Hydrologie 1 (Allgemeine Hydrologie, Quantitative Hydrologie). Borntraeger.

Bloomfield, P. 1976. Fourier analysis of time series: an introduction. J. Wiley \& Sons, New York: 258 pp.

Del Cogliano, D., R. Dietrich, A. Richter, R. Perdomo, J.L. Hormaechea, G. Liebsch \& M. Fritsche. 2007. Regional geoid determination in Tierra del Fuego including GPS levelling. Geologica Acta, 5: 315-322.

Forel, F.A. 1895. Le Léman; monographie limnologique. 2. F. Rouge.

Håkanson, L. 1981. A manual of lake morphometry. Springer.

Hutchinson, G.E. 1957. A treatise on limnology. 1. Wiley \& Sons, New York.

Lippai, H., E. Lodolo, A. Tassone, J.L. Hormaechea, M. Menichetti, J.F. Vilas \& the TESAC Party. 2004. Morphostructure of Lago Fagnano (Tierra del Fuego) and adjacent areas. Bollettino di Geofisica teorica ed applicata, 45(2 suppl.): 142-144.

Lodolo, E., M. Menichetti, R. Bartole, Z. Ben-Avraham, A. Tassone \& H. Lippai. 2003. Magallanes-Fagnano continental transform fault. Tectonics, 22(6): 10.1029/ 2003TC001500.

Mariazzi, A.A., V.H. Conzonno, J. Ulibarrena, J.C. Paggi \& J.L. Donadelli. 1984. Limnological investigation in Tierra del Fuego, Argentina. Biologia Acuatica, 10: 1-30.

Millero, F. J. \& A. Poisson. 1981. International one-atmosphere equation of state of seawater. Deep Sea Res., 28(A): 625-629.

Moritz, H. 1979. Report of Special Study Group No 539 of IAG, Fundamental Geodetic Constants. Technical report presented at XVII General Assembly of IUGG, Canberra.

Mortimer, C.H. 1974. Lake hydrodynamics. Mitt. Internat. Verein. Limnol., 20: 124-197.

Received: July 2009

Accepted: October 2009
Neumann, G. 1941. Eigenschwingungen der Ostsee. Archiv der Deutschen Seewarte und des Marineobservatoriums. Hamburg.

Rabassa, J., A. Coronato, G. Bujalesky, M. Salemme, C. Roig, A. Meglioli, C. Heusser, S. Gordillo, F. Roig, A. Borromei \& M. Quattrocchio. 2000. Quaternary of Tierra del Fuego, Southernmost South America: an updated review. Quat. Int., 68-71: 217-240.

Richter, A., M. Marcos, S. Monserrat, D. Gomis, S. Ruiz, G. Liebsch \& R. Dietrich. 2005. Comparison and combination of coastal and off-shore tide gauge measurements from Eivissa Island, Western Mediterranean. Marine Geodesy, 28: 271-289.

Richter, A., J.L. Hormaechea, R. Dietrich, R. Perdomo, M. Fritsche, D. Del Cogliano, G. Liebsch \& L. Mendoza. 2009. Anomalous ocean load tide signal observed in lakelevel variations in Tierra del Fuego. Geophys. Res. Lett., 36: L05305, doi:10.1029/2008GL036970.

Tuhkanen, S. 1992. The climate of Tierra del Fuego from a vegetation geographical point of view and its ecoclimatic counterparts elsewhere. Acta Bot. Fennica, 145: 1-64.

Van Dam, T., H.-P. Plag, O. Francis \& P. Gegout. 2002. GGFC Special Bureau for Loading: Current status and plans. IERS Technical note, 30: 180-198.

Waldmann, N., D. Ariztegui, F.S. Anselmetti, J.A. Austin, R. Dunbar, C.M. Moy \& C. Recasens. 2008. Seismic stratigraphy of Lago Fagnano sediments (Tierra del Fuego, Argentina) - A potential archive of paleoclimatic change and tectonic activity since the Late Glacial. Geologica Acta, 6: 101-110.

Wunsch, C. \& D. Stammer. 1997. Atmospheric loading and the oceanic Inverted Barometer effect. Rev. Geophys., 35: 79-107. 